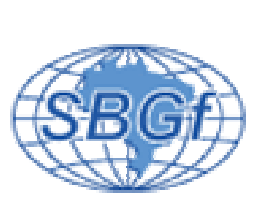

\title{
Aplicação de aerogamaespectrometria à análise de processos geomorfológicos
}

Henrique Angelo Piovesan Dal Pozzo, AeroGeoPhysica Latinoamerica

Eder Cassola Molina, Depto de Geofísica IAG/USP

Dionísio Uendro Carlos, Depto de Geofísica IAG/USP

Jurandyr Luciano Sanches Ross, Depto de Geografia FFLCH/USP

Copyright 2004, SBGf - Sociedade Brasileira de Geofísica

Este texto foi preparado para a apresentação no I Simpósio de Geofísica da Sociedade Brasileira de Geofísica, São Paulo, 26-28 de setembro de 2004. Seu conteúdo foi revisado pela Comissão Tecno-científica do I SR-SBGf mas não necessariamente representa a opinião da SBGf ou de seus associados. E proibida a autorização da SBGf.

\section{Resumo}

O presente trabalho discute como a aerogamaespectrometria pode ser empregada no mapeamento de materiais regolíticos e assim contribuir para a análise e entendimento de processos geomorfológicos em ambientes tropicais úmidos. Foi utilizado como modelo uma área na região de Passa Tempo, Minas Gerais, onde estão disponíveis dados de alta resolução. Os resultados obtidos permitiram compartimentar a atuação de processos geomórficos e de intemperismo na região, auxiliando no desenvolvimento de estratégias de gerenciamento ambiental mais efetivas.

\section{Introdução}

Embora a aerogamaespectrometria seja utilizada essencialmente em exploração mineral e mapeamento geológico, a aplicação em estudos geomorfológicos tem ganhado importância como mostram os trabalhos de Hutchinson (1995), Cook et al. (1996), Dickson et al. (1996), Wilford et al. (1997), Pickup \& Marks (2000) e (2001), Wilford et al. (2001), Roberts et al. (2003) e Thomas et al. (2003). Neste trabalho foi utilizada, como exemplo de aplicação da metodologia empregada, uma área na região de Passa Tempo, Minas Gerais, onde estão disponíveis dados aerogamaespectrométricos de alta resolução e boa qualidade do Projeto Levantamento Aerogeofísico de Minas Gerais, Área 2 - Pitanguí - São João Del Rei - Ipatinga (SEME, 2001). As linhas de vôo foram executadas com espaçamento de $250 \mathrm{~m}$ e as linhas de controle com espaçamento de $2500 \mathrm{~m}$. A altura nominal de vôo foi de $100 \mathrm{~m}$, com intervalo de amostragem de 1 medida por segundo, equivalendo aproximadamente a uma medida a cada 55 metros no terreno.

A área de estudo situa-se geologicamente no Complexo Metamórfico Passa Tempo, um dos complexos que constituem a crosta siálica da porção meridional do Cráton do São Francisco. Esse complexo abrange gnaisses tonalíticos e graníticos, rochas máficas e ultramáficas, migmatitos e granitóides (Figura 1). Os litotipos félsicos ocorrem geralmente difundidos em regiões como corpos graníticos (quartzo-monzonítico/ granodiorítico e alcali-graníticos), na maioria das vezes ricos em feldspato potássico e biotita. Ortopiroxênio está presente nos gnaisses, e é comumente re-alocado por hornoblenda e/ou biotita (Campos et al., 2003). Dentro do contexto geomorfológico, a área de estudo localiza-se no domínio morfoescultural de planaltos e serras do sudeste brasileiro. O padrão morfológico é caracterizado por morros de topos convexos com alto grau de entalhamento e predomínio de altas declividades nos setores de média vertente (30 a 80\%).

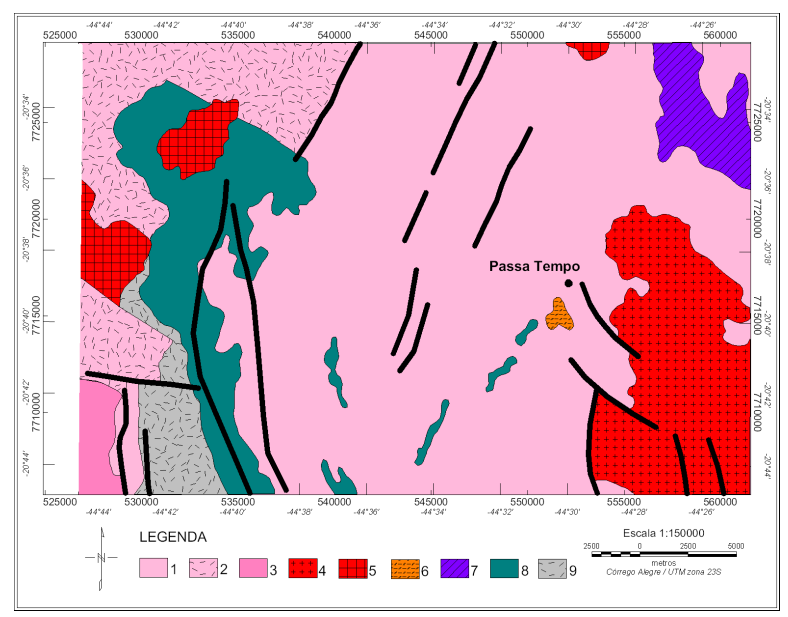

Figura 1 - Mapa geológico esquemático da região de Passa Tempo, MG (Adaptado de Campos et al., 2003). Legenda: 1 - Complexo Metamórfico Passa Tempo - CMPT (granulitos); 2 - CMPT (ortognaisses migmatizados e granodioritos); 3 - CMPT (ortognaisses tonalíticos); 4 - (granitos cinza claros variavelmente deformados); 5 - CMPT (granitos); 6 (granodioritos cinza claros deformados); 7 - (gabros); 8 - Supergrupo Rio das Velhas; 9 - Complexo Metamórfico Bonfim.

\section{Metodologia/ Problema Investigado}

Os levantamentos aerogamaespectrométricos medem a abundância de urânio, tório e potássio na superfície terrestre pela detecção da radiação gama proveniente do decaimento natural dos radionuclídeos das séries do ${ }^{238} \mathrm{U}$ $\left({ }^{214} \mathrm{Bi}\right),{ }^{232} \mathrm{Th}\left({ }^{208} \mathrm{TI}\right)$ e do próprio ${ }^{40} \mathrm{~K}$. A distribuição e concentração desses elementos na superfície variam de acordo com a litologia e com a natureza do intemperismo que o material original foi submetido.

Durante o intemperismo químico e físico, os radioelementos são liberados, redistribuídos e incorporados ao regolito in-situ e transportado. Em muitos casos, os radioelementos característicos de materiais regolíticos diferem sensivelmente de suas fontes subjacentes de rochas, devido à reorganização textural e geoquímica no perfil de intemperismo. Alguns materiais regolíticos alterados tipicamente apresentam perda de K, em razão da sua retirada por lixiviação, e elevados 
valores de $U$ e Th associados com argilas e/ou óxidos de ferro na parte superior do perfil de intemperismo (Dickson \& Scott, 1997). Nesse contexto as respostas gamaespectrométricas podem assumir dois aspectos distintos. Nos afloramentos rochosos ou onde o regolito é pouco espesso, a resposta gamaespectrométrica retrata diretamente a mineralogia e geoquímica primária da rocha. Já em lugares onde o regolito é mais desenvolvido a resposta gamaespectrométrica retrata a mineralogia e geoquímica secundária. Dessa forma, esses aspectos permitem inferir a respeito da gênese e evolução do manto de alteração, que por sua vez expressam fundamentalmente os processos geomórficos nas vertentes e fundos de vale.

Com base nesses pressupostos acima expostos a gamaespectrometria pode ser usada para separar áreas com forte atividade erosiva de áreas com superfícies mais estáveis, onde prevalece o desenvolvimento do manto de alteração, e permite avaliar as atividades deposicionais ao longo dos leitos fluviais.

\section{Resultados}

Os compartimentos indicados com a letra A nos mapas (figuras 2 e 3 ) representam as áreas cujas vertentes possuem alta concentração de $\mathrm{K}$ e alta declividade. Esta característica se deve à mineralogia e geoquímica primária dos litotipos que compõem o Complexo Metamórfico Passa Tempo, geralmente ricos em feldspato potássico e biotita, principais hospedeiros primários de $\mathrm{K}$ na natureza. Tal particularidade sugere a presença de um perfil de alteração jovem, pouco desenvolvido evidenciando que nessas áreas a razão de erosão é superior à razão de intemperismo.

Os setores de topo e vertentes mais suaves com declividades média e baixa apresentam baixa concentração de K (Figura 2) e um enriquecimento do Th com relação ao $\mathrm{K}$ (letra $\mathrm{C}$ nas Figuras 3 e 4 ). O Th comumente se associa aos minerais resistentes e fica preservado nos perfis de intemperismo altamente alterados. Como os litotipos fontes nessa área caracterizam-se por alta concentração de $\mathrm{K}$, a baixa concentração observada desse elemento e o enriquecimento de Th com relação a ele indica superfícies mais estáveis do ponto de vista geomórfico. Neste caso, a razão de intemperismo supera a razão de erosão, permitindo assim um maior desenvolvimento do manto de alteração.

Os compartimentos indicados com a letra B representam as superfícies planas de baixa declividade das planícies aluviais, com alta concentração de K. Nessas áreas de regime deposicional a alta concentração de $\mathrm{K}$ retrata a mineralogia e geoquímica da área fonte (litotipos do Complexo Metamórfico Passa Tempo), sugerindo que o processo deposicional na área está ativo ou pelo menos é recente, uma vez que o $\mathrm{K}$ é facilmente lixiviado.

Esses três padrões de regimes geomórficos acima expostos foram correlacionados e classificados a partir de uma análise de histograma bidimensional, o que permitiu chegar a um modelo de processos geomorfológicos atuantes na área. Os resultados da correlação dos dados gamaespectrométricos e morfométricos (declividade) podem ser observados na Figura 5.

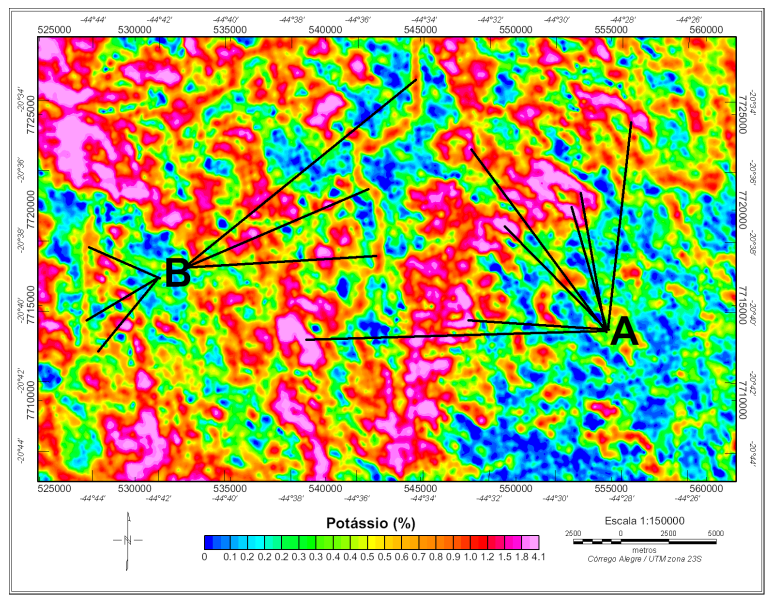

Figura 2 - Mapa de Concentração de Potássio.

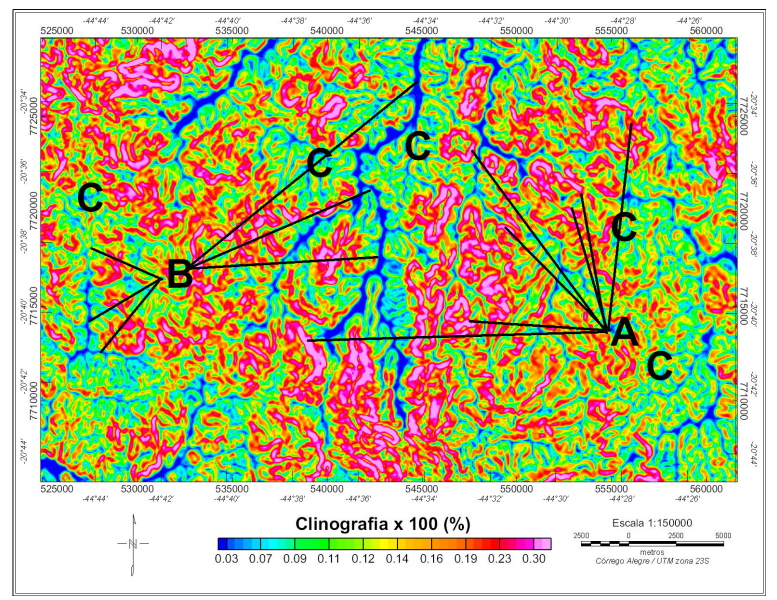

Figura 3 - Mapa de Clinográfico.

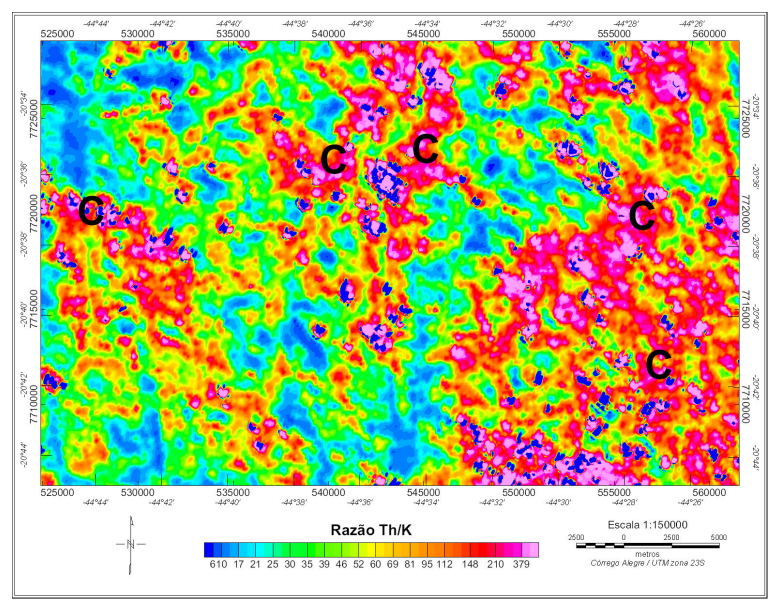

Figura 4 - Mapa de Razão Th/K. 
O modelo superior da Figura 5a apresenta o resultado da classificação e análise dos processos geomórficos atuantes na área de estudo.

A classe 1 (azul escuro) representa as áreas de ocorrência de sedimentação recente onde estão sendo depositados os produtos de alteração do CMPT ricos em $\mathrm{K}$. Pode-se observar essas planícies aluviais ao longo das drenagens principais, destacadas pela alta concentração de K (modelo central da Figura 5a).

A classe 2 (azul claro) representa as áreas onde a razão de erosão é superior a razão de intemperismo, fazendo com que as porções menos intemperizadas do perfil de alteração sejam expostas em razão da forte atividade erosiva nas vertentes com altas declividades.

A classe 3 (verde) representa as áreas onde a razão de intemperismo supera a razão de erosão, favorecendo o desenvolvimento do solo nos setores de topos e vertentes com declividades média a baixa. Nessas superfícies mais estáveis em que a infiltração da água é mais efetiva que o escoamento superficial, elementos solúveis como o $\mathrm{K}$ são retirados pela pedogênese e lixiviação, preservando o Th (modelo inferior da Figura 5a) que se associa aos minerais resistentes e óxidos de ferro e alumínio, gerados durante o processo de alteração.

\section{Discussão e Conclusões}

Os três padrões geomórficos reconhecidos caracterizamse por: áreas com processo deposicional ativo, representadas por planícies aluviais com alta concentração de $\mathrm{K}$; áreas de forte atuação erosiva, caracterizadas por vertentes com altas declividades e alta concentração de $\mathrm{K}$; e áreas com predomínio de desenvolvimento do regolito, associadas às vertentes com baixas e médias declividades, baixa concentração de $\mathrm{K}$ e enriquecimento do Th com relação ao K.

A aplicação da aerogamaespectrometria integrada a dados morfométricos na análise e mapeamento geomorfológico permitiu delinear a atuação dos processos geomórficos na região de Passa Tempo, Minas Gerais. O modelo elaborado com base nessa integração permite avaliar os riscos econômicos e ambientais decorrentes da atuação desses processos na região investigada.

\section{Agradecimentos}

Os autores agradecem à Secretaria de Estado de Minas e Energia (SEME) e Companhia Mineradora de Minas Gerais (COMIG) pelo fornecimento dos dados aerogeofísicos utilizados nesse trabalho e à Agência Nacional do Petróleo (ANP).

\section{Referências}

Campos, J. C. S.; Carneiro, M. A.; Basei, A. S. 2003. U$\mathrm{Pb}$ evidence for Late Neoarchean crustal reworking in the southern São Francisco Craton (Minas Gerais, Brazil). Anais da Acad. Bras. Cienc., vol. 75 (4): 497-511.

Cook, S. E. et al. 1996. Application of airborne gamma radiometric data for soil mapping. Australian Journal of Soil Research, vol. 34 (1):183-194.
Dickson, B. L.; Fraser, S. J.; Kinsey-Henderson, A. 1996. Interpreting aerial gamma-ray utilizing geomorphological and weathering models. Journal of Geochemical Exploration, 57:75-88.

Dickson, B. L.; Scott, K. M. 1997. Interpretation of aerial gamma-ray surveys - adding the geochemical factors. AGSO Journal of Australian Geology \& Geophysics, vol.17 (2):187-200.

Huntchinson, S. M. 1995. Use of magnetic and gammaray measurements to investigate erosion and sedimentation in a British upland catchment. Earth Surface Processes and Landforms, 20:293-314.

Minty, B. R. S. 1997. Fundamental of airborne gamma-ray spectrometry. AGSO Journal of Australian Geology \& Geophysics, vol.17 (2):39-50.

Pickup, G.; Marks, A. 2000. Identifying large-scale erosion and deposition process from airborne gamma radiometrics and digital elevation data in a weathered landscape. Earth Surface Processes and Landforms, 25: 535-557.

Pickup, G.; Marks, A. 2001. Regional-scale sedimentation process models from airborne gamma ray remote sensing and digital elevation data. Earth Surface Processes and Landforms, 26:273-293.

Roberts, L. M. et al. 2003. High-resolution ground based gamma-ray spectrometry and electromagnetics to assess regolith properties, Boorowa, NSW. Advances in Regolith, 352-357.

SEME - Secretaria de Estado de Minas Gerais. 2001. Levantamento Aerogeofísico de Minas Gerais, Área A2 Pitanguí - São João Del Rei - Ipatinga. Relatório Final. Texto técnico, vol.1, $80 \mathrm{p}$.

Thomas, M.; Fitzpatrick, R. W.; Heinson, G. S. 2003. Mapping complex soil-landscape patterns using radiometric $\mathrm{K} \%$ : a dry saline land farming area case study near Jamestown, SA. Advances in Regolith, 411-416.

Wilford, J. R.; Bierwirth, P. N.; Craig, M. A. 1997. Application of airborne gamma-ray spectrometry in soil/regolith mapping and applied geomorphology. AGSO Journal of Australian Geology \& Geophysics, vol. 17(2): 201-216.

Wilford, J. R.; Dowling, T.; Braaten, R. 2001. Rapid Mapping of digital and salt stores, using airborne radiometrics and digital elevation models. AGSO Research Newsletter, 34:33-40. 


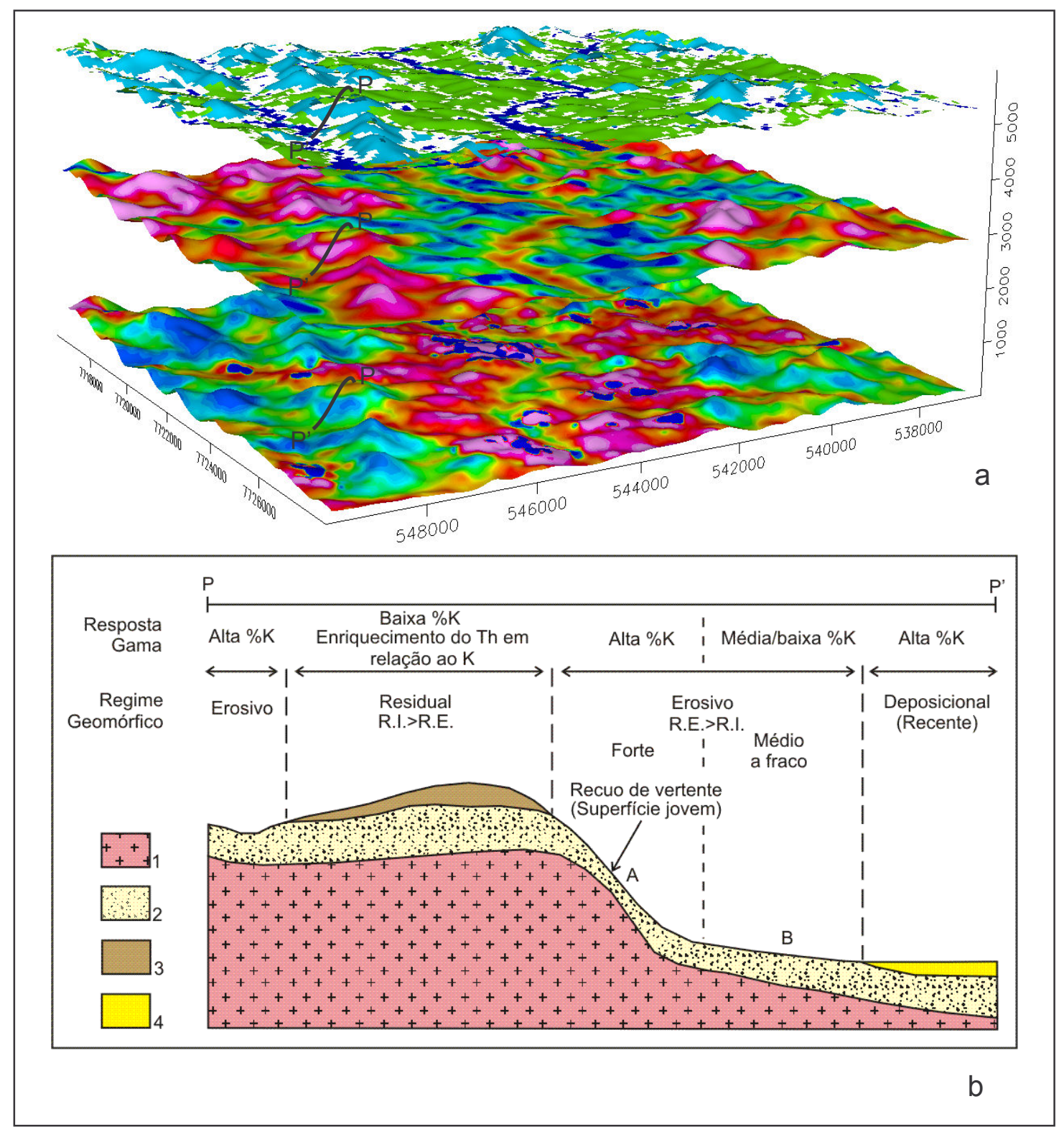

Figura 5 - a) O modelo inferior mostra a razão de Th/K na superfície do relevo. O modelo central mostra a concentração de $K$ na superfície do relevo. O modelo superior mostra o resultado da classificação dos processos geomórficos nas vertentes e fundos de vale. B) Modelo sintético da relação entre os processos geomórficos e a resposta gamaespectrométrica para a área de Passa Tempo, MG (Perfil P-P'). O modelo foi concebido a partir de Wilford et al. (1997). Legenda: 1 Matriz rochosa do Complexo Metamórfico Passa Tempo; 2 - Material saprolítico, com fragmentos da matriz rochosa e baixo grau de alteração. 3 - Material residual, geralmente arenoso, altamente alterado; A - Zona de recuo de vertente, com perfil de intemperismo pouco desenvolvido; B - Zona de menor atuação de processos erosivos em razão da diminuição da energia cinética do escoamento superficial; R.E. - Razão de erosão; R.I. - Razão de Intemperismo. 